\title{
The Role of Green Human Resource Management Practices on Environmental Management in Tanzanian Industries: Lessons from Mohammed Enterprises Tanzania Limited
}

\author{
Kelvin Magoko Mwita*, Eliza Mwakasangula \\ Department of Public Service and Human Resource Management, Mzumbe University, Morogoro, Tanzania \\ Email address: \\ kmwita@mzumbe.ac.tz (K. M. Mwita), efaty@mzumbe.ac.tz (E. Mwakasangula) \\ ${ }^{*}$ Corresponding author
}

To cite this article:

Kelvin Magoko Mwita, Eliza Mwakasangula. The Role of Green Human Resource Management Practices on Environmental Management in Tanzanian Industries: Lessons from Mohammed Enterprises Tanzania Limited. Science Journal of Business and Management.

Vol. 8, No. 2, 2020, pp. 57-63. doi: 10.11648/j.sjbm.20200802.12

Received: March 23, 2020; Accepted: April 20, 2020; Published: May 14, 2020

\begin{abstract}
In the last few years, global concerns have increased regarding environmental issues. These concerns generated more pressure and necessitated businesses and industries to develop and use green management by adopting green practices and products. Green HRM practices have emerged to be one of effective management initiatives in environmental management. Tanzania intends to be a semi-industrialized country and the government has been showing recommendable efforts to ensure that the goal is successfully achieved. In considering industrialization process in Tanzania there is a need to look for best practices in dealing with the side effects of industrialization to ensure that the process does not only benefit the economy but also protects the planet earth. This study used a case study design to learn how industries use Green HRM practices to ensure that their operations do not lead to environmental degradation. The study found that green recruitment and selection, green training, green performance management and green rewards management are essential in environmental management. The study recommends industries to formalize and adopt green human resource management practices in order to increase environmental management performance for successful industrialization of the Tanzania economy.
\end{abstract}

Keywords: Environmental Management, Green HRM, Green Management, Tanzania, Green Economy

\section{Introduction}

Globally, industrialization is rapidly taking place in different regions. As a result, countries have been experiencing an increase in levels of production, employment and economic development in general [1]. Industrial growth also comes with its severe effects. It causes tremendous stress on the entire bionetwork and natural system components like water, air, soil, bio-diversity including surrounding ecosystem [2]. Manufacturing industries have been finger pointed for their significant contribution on environmental pollution [3]. To deal with environmental issues, various green practices such as green procurement, green marketing, and green accounting have been implemented by various firms to ensure that these firms operate sustainably and do not become harmful to the environment.

The concept of environmental management has remained on the agenda of the corporate world aiming at finding ways of reducing and avoiding adverse effects of industrial activities to the environment [4]. Recently, green human resource management has emerged as one of the ways of ensuring that human resource management functions contribute in environmental management. Green Human Resource Management is an integration of environmental management and human resource management which aims at making HR functions more environmental friendly. HRM scholars and practitioners alike have been relatively slow to engage in the ongoing discussions and debates concerning environmental management [5]. This calls out for more scholarly studies on how HRM can contribute towards environmental management.

Tanzania intends to be a semi-industrialized country and the government has been showing recommendable efforts to ensure that the goal is successfully achieved [6]. In the 
industrialization process, Tanzania has to look for best practices in dealing with the side effects of industrialization to ensure that the process does not only benefit the economy but also protects the planet earth. The topic of green HRM is increasingly drawing attention of management scholars. Despite its importance to various stakeholders yet there are limited scholarly works in the area [7]. Generally, the available few empirical works in the literature show that green HRM is one of the effective ways of environmental management and a strategy for business sustainability. Identification of green HRM practices and how Tanzanian industries can adopt them in protecting environment is important in order to make industrialization process in Tanzania less harmful to the environment.

Purpose of the Study

The study aimed at studying how green human resource management is practiced in Tanzanian industries and its role on environmental management in the country. Specifically, the study focused on studying the role of three green HRM practices namely, green recruitment and selection, green training and green performance management

\section{Literature Review}

\subsection{Conceptual Definitions}

\subsubsection{Green Human Resource Management (GHRM)}

GHRM refers to the use of HRM policies, philosophies and practices to promote sustainable use of resources and prevent harm arising from environmental concerns within business organizations [8]. It is often used to refer to the contribution of HR policies and practices towards the broader corporate environmental agenda of protection and prevention of natural resource [9].

\subsubsection{Green Recruitment and Selection}

Green recruitment and selection involves recruiting employees with consideration that newly recruited employees should be responsible for protecting the environment. Complementing this, the recruits are also enthusiastic, and to some extent, passionate about working for an environmental friendly "green" company [10]. Candidates' green awareness is the basic aspect of green recruitment and selection and involves personality factors that enable organization's environmental goals to be achieved such as green consciousness, conscientiousness and the agreeableness of candidates. Employees who are of environmental value have been found to actively enhance their environmental knowledge in the operational process, which in turn enhances the environmental performance of their firms [11]. Moreover, the process of recruiting and selecting employees should be as eco-friendly as possible and it normally focuses on being paperless to reduce the use of papers.

\subsubsection{Green Training}

Green training refers to a system of activities that motivate employees to learn environmental protection skills and pay attention to environmental issues, which is essential in accomplishing environmental objectives [12]. It is also, a process of impacting employees with knowledge and skills focusing on making them capable of using various means of protecting the environment. Moreover, the process itself should not contribute towards environmental pollution. In green training, trainers normally use methodologies that are eco-friendly.

\subsubsection{Green Performance Management}

Generally, there is a necessity to explore the green performance of jobs in the context of Green HRM because at individual level green performance of each job is critical in reducing overall negative environmental impact of the organization [13]. Green performance management consists of issues related to environmental concerns and policies of the company [10]. Green performance management involves setting green goals for individual employees, groups and the whole organization and putting in place mechanisms to ensure that these goals are achieved.

\subsection{AMO Theory}

AMO stands for ability, motivation and opportunity to participate. The theory postulates that an HRM system should be designed to meet employees' needs for skills and motivation and after meeting these needs, provide them with opportunities to use their abilities in various roles [14]. The theory explains that HRM works by increasing employees' ability through attracting and developing high-performing employees, enhancing employees' motivation and commitment through practices such as contingent rewards and effective performance management. This is followed by providing employees with the opportunity to engage in knowledge-sharing and problem solving activities via employee involvement (EI) programmes [15]. The AMO framework has been widely accepted in HRM literature for explaining the linkage between human resource practices and performance [16]. The relevance of the theory in this study can be well explained by the fact that, for employees to perform well in green initiatives or environmental management at workplaces firstly, they are supposed to have an ability to do so and therefore skill acquisition is required. Secondly, they have to be motivated to do so through various rewards and thirdly, they have to be engaged or given an opportunity to take part in green initiatives.

\subsection{Empirical Review}

Green HRM is essential to contemporary organizations. It is linked to corporate social responsibility, business performance and enhancing environmental sustainability. Organizations that are willing and able to practice Green HRM are more likely to attract more customers, shareholders and comply with legal and ethical standards [17].

Pham, Tuckova and Phan conducted a quantitative survey that involved 209 respondents. The study demonstrated that employee commitment towards the environment is a function of green training, green reward management and organizational culture. The study identified one of very 
important factors, that it, organizational culture for green HRM to work out well. This implies that, no matter how important green HRM is, in absence of supportive organizational culture it won't be significantly effective [18]. The issue of organizational culture as an enabling factor for green behavior was also insisted in the study of Esen and Kalistan which opined that for green HRM to facilitate environmental sustainability it is crucial that organizational culture is well shaped to accommodate green HRM practices. The study further explains that Green human resource management (GHRM) which also develops corporate reputation can foster employees' involvement in environmental practices and make them motivated to involve themselves in green activities [19]. This is also consistent with the study of AnuSingh and Shikha which was done in India. The study found that top management commitment among other things plays a crucial role in the influence of Green HRM to the perceived environmental performance [20].

A recent study of Hameed, Khan, Islam, Sheikh and Naeem shows that green HRM has a positive significant effect on organizational citizenship behavior toward environment (OCBE). Moreover, green employee empowerment was found to be an enabling factor in the effect of green HRM on OCBE [21]. It should be noted that for organizations to perform well in any aspect usually employees play a key role in that performance hence the study confirms the essence of offering employees with necessary skills for OCBE. The literature offers limited empirical studies which have been done in Africa on green HRM in general and those linking green HRM and environmental management in specific. A study which was done in Kenya by Owino and Kwisira [22] attempted to assess the influence of selected Green Human Resource Management Practices on Environmental Sustainability. The study found a weak relationship between green employee outsourcing and environmental sustainability. Green training and development was also found to have a weak relationship with environmental sustainability. Green occupation health and safety was found to have a positive significant relationship with environmental management. Moreover, green performance management had a positive significant influence on environmental sustainability. As previously noted, lack of sufficient studies in the area makes it difficult to make comparative analysis with other empirical studies done in Africa. This shows that more studies in Africa on green HRM are needed to bridge this empirical gap.

\section{Methodology}

Qualitative and quantitative data were collected by using interviews and a questionnaire respectively from Mohamed Enterprises Tanzania Limited (METL). A questionnaire involved a 5 point likert scale considering a cut-off point of 3. METL was ideal to be involved because of her experience in manufacturing various products in Tanzania and having diverse industries in terms of types of output produced by the industries. MeTL Group is a leading economic force in Tanzania with major investments and successful operating companies in key business sectors. The Group employs more than 24,000 people across the country, in various areas such as trading, agriculture, manufacturing, energy and petroleum. Other areas include financial services, mobile telephony, infrastructure, real estate, transport, logistics and distribution. Seventy four (74) respondents were involved in the study which included 4 human resource managers who were purposively sampled and 70 employees who were conveniently sampled. Data from the human resource managers were collected through the use of interviews and an online survey was used to collect data from other employees. It was crucial to include HRs in the study since they are directly dealing with day-to-day functions of human resource management. Other employees were included in the study to confirm information provided by HRs as they are the involved in the day-to-day activities of the industries. METL has a total of 13 manufacturing industries across the country.

\section{Findings and Discussion}

\subsection{Study's Respondents}

The study initially intended to collect data from 78 employees working in the industries and 4 human resource personnel who were supposed to make a total of 82 respondents. However, the study attained a response of 70 employees and $4 \mathrm{HR}$ personnel. Out of 74 respondents 44 were female $(59.5 \%)$ and 30 were male $(40.5 \%)$.

\subsection{Green Recruitment and Selection at METL}

Through the interviews conducted it was found that METL have policies which are crucial in guiding recruitment and selection to ensure the process contributes towards environmental management by assisting recruitment and selection of people with 'green minds'. Websites and emails are normally used to make sure the use of papers is minimized. Assessment of job candidates normally involves assessing whether job applicants are knowledgeable and skilled on environmental conservation. It was found that, this is very important since industries recruit people who are ecofriendly and therefore the chance of environmental pollution by recruited employees is minimized. The study found that when recruitment and selection considers the need for environmental sustainability it shows how serious the industries are in green agendas and this sends a strong message to new recruits on how committed the industries are towards environmental management.

One of the interviewees commented that,

"keeping our workplace and the surrounding environment green is part of CRS (Corporate social responsibility) and we are committed to comply with legislations which require us to make environmental conservation one of our top priorities. Considering this fact, we usually reflect this commitment in our hiring process to ensure we employ and retain people who will help us on environmental 


\section{conservation"}

Mehta and Chugan opined that through green recruitment and selection new recruits are able to inculcate and get familiarized with the culture of the organization, right from the beginning and therefore it is important to let them understand how committed firms are in green management [23]. It is also recommended by Ahmad that organizations should recruit candidates who have green bend of mind since it makes it easy for firms to induct professionals who are aware of sustainable processes and familiar with basics like recycling, conservation, and creating a more logical world [10]. The practices show that it is important to have strategies and policies that will guide organizations in recruiting employees with green mindsets [24]. This implies that, if green recruitment and selection is institutionalized by using recruitment and selection policies firms are likely to take it more seriously and become part of the organizational culture.

\subsection{Green Training at METL}

To ensure newly recruited employees are aware of environmental management interventions, induction training among other things focus on equipping the employees with knowledge and skills on environmental management. Recruited employees are also made aware of the policies and other guidelines designed to control environmental pollutions. Responses from the interviews show that industries benefit from these training programs since they contribute towards reduction and avoidance of environmental pollution in their respective industries.

Apart from induction training programs that are special for recruits, employees at all levels are regularly offered with environmental management training to ensure they are all time updated with skills necessary to make them capable of using various environmental management interventions in their day to day operations.

To make sure that training programs do not make use of papers unnecessarily these programs are conducted with an assistance of various technologies such as the use of LCD projectors and the learning materials are largely disseminated by using electronic means. Through the interviews, it was noted that the use of papers cannot be hundred percent avoided but industries are normally advised to make their use as minimal as possible. These training programs do not only emphasize employees to take care of the environment at their working areas but also even when they are out of their working environment.

Findings from questionnaires are consistent with what was found in interviews. Three questions concerning green training were asked to 70 respondents who filled the questionnaires. The study sought to find out whether employees are trained on issues relating to environmental management. It was found that $0 \%$ said they never get trained, 1.4\% responded that they are rarely trained, $20 \%$ said they are sometimes trained, $45.7 \%$ are usually trained and $32.9 \%$ responded that they are always trained. The study further calculated the weighted mean which was found to be 4.1 out of 5 . The cut-off point for the study was 3.0 which implies that training on issues related to environmental management is satisfactorily done by the industries.

Regarding avoiding the use of papers in training programs $2.9 \%$ responded that their industries never do anything to make sure training programs use as minimum papers as possible, $5.7 \%$ responded that they rarely avoid the use of papers, $17.1 \%$ responded that they sometimes do, $48.6 \%$ responded that they usually do while $28.6 \%$ responded that their industries always do. The weighted mean for this question was 4.0 which is above 3.0 cut-off point. This means the efforts to minimize the use of papers in training programs by METL are recommendable.

Further, the study assessed the use of various technologies in training programs such as videos and the internet technology in sending training materials as one of ways of reducing the use of papers. It was observed that MeTL was slowly introducing online training and enrolling managers and corporate staff on online learning platforms which are self-paced and easily track-able. Also other platforms which were found to be encouraged by management for learning purposes are $e d X$ and Udemy. It was found that $7.1 \%$ of the respondents believed that the technologies are never used, $17.1 \%$ responded that they are rarely used, $20 \%$ responded that are sometimes used, $32.9 \%$ responded that they are usually used and $27.1 \%$ responded that the technologies are always used. With a weighted mean of 3.7 out of 5 which is above the set cut-off mean it shows that the technologies are sufficiently integrated in training programs.

Table 1. Responses on Green Training.

\begin{tabular}{|c|c|c|c|c|c|c|}
\hline \multirow{2}{*}{ Statement } & \multicolumn{6}{|c|}{ Frequency and Percentage } \\
\hline & $\mathbf{N}$ & $\mathbf{R}$ & $\mathbf{S}$ & $\mathbf{U}$ & $\mathbf{A}$ & WM \\
\hline We are trained on issues relating to environmental management & $0(0 \%)$ & $1(1.4 \%)$ & $14(20 \%)$ & $32(45.7 \%)$ & $23(32.9 \%)$ & 4.1 \\
\hline $\begin{array}{l}\text { Our industry does anything possible to make sure our training programs use as } \\
\text { minimum papers as possible? }\end{array}$ & $2(2.9 \%)$ & $4(5.7 \%)$ & $12(17.1 \%)$ & $34(48.6 \%)$ & $20(28.6 \%)$ & 4.0 \\
\hline Organization uses various technologies to facilitate training programs. & $5(7.1 \%)$ & $12(17.1 \%)$ & $14(20 \%)$ & $23(32.9 \%)$ & $19(27.1 \%)$ & 3.7 \\
\hline
\end{tabular}

$\mathrm{N}=$ Never, $\mathrm{R}=$ Rarely, $\mathrm{S}=$ Sometimes, $\mathrm{U}=$ Usually, $\mathrm{A}=$ Always, $\mathrm{WM}=$ Weighted Mean

Mashala recommends that when human resource departments conduct training needs analysis, environmental based skill and knowledge gaps should be considered so as to bring in informed decisions for employee environmental training [25]. This is one of important aspects towards effective green training since training programs should be tailored to address specific green needs of firms. Training is an important strategy to enable employees in controlling 
wastage (in terms of both prevention and reduction) in the organization. This means it is important for organizations to design and implement effective training programs that can help employees in understanding green practices, policies and procedure [26].

\subsection{Green Performance Management at METL}

This study found that apart from other goals that individual employees are set to achieve they are also assigned green goals which aim at making industries more environmental friendly. These goals are normally set collaboratively between employees and their respective immediate supervisors. Through the interviews it was found that these goals should be owned by the employees themselves since they need a certain level of commitment to achieve hence participation is necessary.

Despite that the general performance appraisal is regularly done, employees are also assessed on how they contribute towards keeping their industries green. This plays an important role in motivating employees to take environmental conservation seriously.

To make sure the culture of environmental friendliness is emphasized those employees who demonstrate efforts in achieving green goals tend to be recognized by management. Admittedly, this was not found to be done sufficiently across all the industries.

Questionnaires were also involved to collect data from employees regarding the issue of green performance management. Firstly, the study sought to establish whether individual employees are given goals that focus on conserving or protecting environment. Out of 70 respondents $4.3 \%$ respondents that green goals are never set, $7.1 \%$ responded that the goals are rarely set, $20 \%$ responded that goals are sometimes set, $42.9 \%$ said the goals are usually set and $25.7 \%$ admitted that these goals are always set. From this question, the calculated weighted mean was found to be 3.8 which implies that generally the respondents agreed that green goals are set by their respective industries.

The study also assessed whether employees' activities are monitored to ensure that they don't cause harmful effects to the environment. Two point nine percent $(2.9 \%)$ of the respondents responded that this is never done, $11.4 \%$ responded that it is rarely done, $14.3 \%$ responded that it is sometimes done, $41.4 \%$ responded that it is usually done and $30 \%$ responded that is always done. A weighted mean of 3.8 out of 5 was found which implies that monitoring of employees' activities is done satisfactorily by the industries to ensure they do not lead to environmental pollution.

Additionally, the respondents were asked to tell whether employees who perform well in protecting/conserving the environment are recognized or rewarded. Out of 70 employees $27.1 \%$ responded never, $28.6 \%$ responded rarely, $5.7 \%$ responded sometimes, $24.3 \%$ responded usually and $22.9 \%$ responded always. On rewarding employees who perform well in protecting environment the weighted mean was found to be 3.0. This means that the industries' performance in this area is generally average.

Table 2. Responses on Green Performance Management.

\begin{tabular}{|c|c|c|c|c|c|c|}
\hline \multirow{2}{*}{ Statement } & \multicolumn{6}{|c|}{ Frequency and Percentage } \\
\hline & $\mathbf{N}$ & $\mathbf{R}$ & $\mathbf{S}$ & $\mathbf{U}$ & $\mathbf{A}$ & WM \\
\hline Individuals are given/set goals that aim at conserving environment at workplace & $3(4.3 \%)$ & $5(7.1 \%)$ & $14(20 \%)$ & $30(42.9 \%)$ & $18(25.7 \%)$ & 3.8 \\
\hline $\begin{array}{l}\text { Our industry has a mechanism of monitoring activities of employees to } \\
\text { ensure they don't pollute the environment }\end{array}$ & $2(2.9 \%)$ & $8(11.4 \%)$ & $10(14.3 \%)$ & $29(41.4 \%)$ & $21(30 \%)$ & 3.8 \\
\hline $\begin{array}{l}\text { Employees who perform well in protecting/conserving environment are } \\
\text { recognized/rewarded. }\end{array}$ & $19(27.1 \%)$ & $20(28.6 \%)$ & $4(5.7 \%)$ & $17(24.3 \%)$ & $16(22.9 \%)$ & 3.0 \\
\hline
\end{tabular}

$\mathrm{N}=$ Never, $\mathrm{R}=$ Rarely, $\mathrm{S}=$ Sometimes, $\mathrm{U}=$ Usually, $\mathrm{A}=$ Always, $\mathrm{WM}=$ Weighted Mean

Tang, Chen, Jiang, Paille and Jie recommended creation of green performance indicators which means establishing a series of green criteria for all members in performance appraisals, covering topics such as environmental incidents, environmental responsibilities, reduction of carbon emissions, and communicating of environmental concerns and policies [11]. Having these performance indicators will obvious make performance appraisal process easier.

Arulrajah, Opatha, and Nawaratne insisted that the sustainability of organization's environmental performance is highly dependent on the green reward management practices of the organizations [13]. Regarding the fact that green HRM is taking its shape in various organizations it is important to offer rewards to those engaging in ensuring that their workplaces are green. Mehta and Chugan argued that compensation and reward system is the leverage to force the change in the organization in the direction of green environmental performance and culture and therefore it has to be part of performance management as a means for improving employee performance in achieving green goals [27]. In this regard, industries have to establish reward packages to reinforce green behaviours among employees for effective environmental management.

\section{Conclusion and Recommendations}

Green human resource management plays an important role towards environmental sustainability in manufacturing industries. Green HRM stands as a vehicle towards building green culture in industries especially when industries are committed in recruiting employees with green attitude, training employees on how to make and keep the environment green as well as having a performance management system that focuses on improving performance of individuals and teams on environmental management. Having policies that guide green HRM is important for 
effectiveness of green HRM practices.

To make sure that Green HRM contributes towards sustainable industrialization this study recommends the following;

1) Formulation of policies that intend to facilitate effective green HRM in industries

2) Green HRM commitment should be reflected in visions, missions and core values of industries to build and strengthen green culture among employee in the industries

3) More researches have to be done in the area of green HRM to come up with more green HRM practices for environmental sustainability

4) Learning institutions should develop curricula which focus on producing experts in the area of green HRM for effective green management in industries and other firms.

\section{References}

[1] Ndiaya, C. \& Lv, K. J. (2018) Role of Industrialization on Economic Growth: The Experience of Senegal (1960-2017). American Journal of Industrial and Business Management, 8, 2072-2085. DOI: 10.4236/ajibm.2018.810137.

[2] Patnaik, R. (2018). Impact of Industrialization on Environment and Sustainable Solutions - Reflections from a South Indian Region. IOP Conf. Series: Earth and Environmental Science. doi: 10.1088/17551315/120/1/012016.

[3] Lohchab, R. K. \&Saini, J. K. (2018). Industrial Pollution Management. Haryana, India: IAHRW Publications Private Limited.

[4] Nyirenda, G. \&Ngwake, C. C. (2014). Environmental management practices for sustainable development: agenda for harmonization. Environmental Economics, 5 (1), 76-85.

[5] Jackson, S. E., Renwick, D. W., Jabbour, C. J., \& MullerCamen, M. (2011). State-of-the-Art and Future Directions for Green Human Resource Management. German Journal of Research in Human Resource Management, 25 (2), 100-116.

[6] URT (2011). Integrated Industrial Development Strategy. Ministry of Industry and Trade of United Republic of Tanzania. Dar es Salaam.

[7] Uddin, M. M. \& Islam, R. (2015). Green HRM: Goal Attainment through Environmental Sustainability. The Journal of Nepalese Business Studies, 9 (1), 13-19.

[8] Zoogah, D. B. (2011). The dynamics of green HRM behaviors: A cognitive social information processing approach. Zeitschriftfür Personal for schung, 25 (2), 117-139.

[9] Parveen, S. M. (2018). Green Human Resource Management. International Journal of Research and Analytical Reviews, 5 (3), 251-254.

[10] Ahmad, S. (2015). Green Human Resource Management: Policies and practices. Cogent Business \& Management, 2 (1), 1-13, DOI: 10.1080/23311975.2015.1030817.

[11] Tang, G., Chen, Y., Jiang, Y., Paille, P. \&Jie, J. (2017). Green human resource management practices: scale development and validity. Asia Pacific Journal of Human Resources, doi:

\section{$10.1111 / 1744-7941.12147$}

[12] Jabbour, C. J. C. (2011). How green are HRM practices, organizational culture, learning and team work? A Brazilian study. Industrial and Commercial Training, 43 (2), 98-105.

[13] Arulrajah, A. A., Opatha, H. H., \& Nawaratne, N. N. (2015). Green Human Resource Management Practices: A Review. Sri Lankan Journal of Human Resource Management, 5 (1), 1-16.

[14] Appelbaum, E., Bailey, T., Berg, P., \& Kalleberg, A. (2000). Manufacturing Advantage: Why High Performance Work Systems Pay Off. Ithaca, New York: Cornell University Press.

[15] Renwick, D. W., Redman, T.\& Maguire, S. (2012). Green Human Resource Management: A Review and Research Agenda. International Journal of Management Reviews, 15 (1), 1-14.

[16] Marin-Garcia, J. A. \&Toman, J. M. (2016). Deconstructing AMO framework: A systematic review. Intangible Capital, 12 (4), 1040-1087.

[17] Mwita, K. M. (2019). Conceptual Review of Green Human Resource Management. East African Journal of Social and Applied Sciences, 1 (2), 13-20.

[18] Pham, N. T., Tuckova, Z., \& Phan, Q. P. (2019). Greening human resource management and employee commitment towards the environment: an interaction model. Journal of Business Economics and Management, 20 (3), 446-465. https://doi.org/10.3846/jbem.2019.9659

[19] Esen, E. \& Kalistan, O. (2019). Green human resource management (GHRM) and environmental sustainability. Press Academia Procedia (PAP), 9, 58-60. http://doi.org/10.17261/Pressacademia.2019.1065.

[20] AnuSingh, L. \& Shikha, G. (2015). Impact of Green Human Resource Factors on Environmental Performance in Manufacturing Companies: An Empirical Evidence) International Journal of Engineering and Management Studies, 6 (1) 23-30.

[21] Hameed, Z., Khan, I. U., Islam, T., Sheikh, Z. and Naeem, R. M. (2020), "Do green HRM practices influence employees' environmental performance?" International Journal of Manpower, Vol. ahead-of-print No. ahead-of-print. https://doi.org/10.1108/IJM-08-2019-0407

[22] Owino, W. A. \& Kwasira, J. (2016). Influence of Selected Green Human Resource Management Practices on Environmental Sustainability at Menengai Oil Refinery Limited Nakuru, Kenya. Journal of Human Resource Management, 4, (3), 19-27. doi: 10.11648/j.jhrm.20160403.11

[23] Mehta, K. \& Chugan, P. K. (2015). Green HRM in Pursuit of Environmentally Sustainable Business. Universal Journal of Industrial and Business Management, 3 (3), 74-81. DOI: 10.13189/ujibm.2015.030302.

[24] Hussain, A. (2018). Green Human Resource Management Practices in Organizations: A comprehensive Literature review. Journal of Human Resource Management Research and Analysis, 2 (1), 112-117.

[25] Mashala, Y. M. (2018). Green Human Resource Management and Environmental Sustainability in Tanzania: A Review and Research Agenda. International Journal of Academic Multidisciplinary Research, 2 (12), 60-68. 
63 Kelvin Magoko Mwita and Eliza Mwakasangula: The Role of Green Human Resource Management Practices on Environmental Management in Tanzanian Industries: Lessons from Mohammed Enterprises Tanzania Limited

[26] Krithika, J., Divya Priyadharshini, N. \&GokulaPriya, J. (2019). Green HRM - Practices In Organisations. Journal of Business and Management, 21 (3), 74-77.
[27] Mehta, N. \& Chugan, P. K. (2016). Developing High Performance Work System in Retail Outlet. New Delhi: Excel India Publishers. 